\title{
Effect of additive calcium administration on
}

\section{FGF23 levels in patients with mild chronic kidney disease treated with calcitriol: a randomized, open-labeled clinical trial}

\author{
This article was published in the following Dove Press journal: \\ Therapeutics and Clinical Risk Management \\ 14 August 2017 \\ Number of times this article has been viewed
}

\author{
Nayoung Han ${ }^{1, *}$ \\ Su Hyun Hong ${ }^{1,2, *}$ \\ Yon Su Kim ${ }^{3}$ \\ Dong Ki Kim ${ }^{3}$ \\ In-Wha Kim' \\ Eunhee $\mathrm{Ji}^{4}$ \\ Jung $\mathrm{Mi} \mathrm{Oh}^{1}$
}

'Research Institute of Pharmaceutical Sciences, College of Pharmacy, Seoul National University, Seoul, ${ }^{2}$ Pharmaceutical Standardization Division, Drug Evaluation Department, National Institute of Food and Drug Safety Evaluation, Ministry of Food and Drug Safety, Chungcheongbuk-do, ${ }^{3}$ Division of Nephrology, Department of Internal Medicine, Seoul National University Hospital, Seoul, ${ }^{4}$ College of Pharmacy, Gachon University, Incheon, Republic of Korea

*These authors contributed equally to this work
Correspondence: Jung Mi Oh

College of Pharmacy and Research

Institute of Pharmaceutical Sciences,

Seoul National University, I Gwanak-ro,

Gwanak-gu, 08826 Seoul,

Republic of Korea

$\mathrm{Tel}+8228807736$

Fax +82 27669560

Email jmoh@snu.ac.kr
Background: The purpose of the present study was to determine the effect of additional calcium carbonate treatment on fibroblast growth factor 23 (FGF23) levels in patients treated with calcitriol.

Methods: In this randomized, open-labeled, and parallel-group study, a total of 30 patients with early chronic kidney disease (CKD) and vitamin D deficiency were randomly assigned to two groups and received interventions for 8 weeks: 1) a combination of calcium carbonate and calcitriol group; and 2) calcitriol only group. The primary outcome was the difference in percentage change of serum FGF23 levels from baseline between the two groups. Secondary end points included the changes in serum levels of calcium, phosphate, parathyroid hormone (PTH), and 25-hydroxyvitamin $\mathrm{D}_{3}(25(\mathrm{OH}) \mathrm{D})$ from baseline.

Results: Serum FGF23 levels were more elevated in the combination group than in the calcitriol-alone group. However, both mean change and percentage change in the serum FGF23 levels during the 8-week period were not significantly different between the two groups. Serum calcium level was increased significantly only in the combination treatment group. There was no significant difference in percentage change of serum calcium levels between the two groups. In addition, changes in serum levels of phosphate, $25(\mathrm{OH}) \mathrm{D}$, or PTH were not significantly different between the two groups. In correlation analysis, changes in serum FGF23 levels were positively correlated with changes in serum calcium and phosphate levels, but not with changes in 25(OH)D or PTH levels. No serious adverse events were observed, however, there was one case of mild gastrointestinal discomfort.

Conclusion: This study revealed that additional calcium carbonate treatment significantly increased serum FGF23 levels in patients treated with calcitriol, with their synergistic effect in promoting intestinal calcium absorption. This suggests that serum FGF23 levels should be monitored regularly, especially in those who use combination of vitamin D and calcium carbonate from the early stages of CKD.

Keywords: fibroblast growth factor-23, vitamin D deficiency, calcium carbonate, calcitriol, mineral and bone disorder

\section{Background}

Vitamin D deficiency is highly prevalent in patients with chronic kidney disease (CKD), and it can be exacerbated in renal failure. ${ }^{1}$ It has been known that vitamin D deficiency itself affects calcium, phosphorus, and bone metabolism, referred to as chronic kidney disease-mineral and bone disorder (CKD-MBD). ${ }^{2}$ In addition, 
vitamin D deficiency leads to increased parathyroid hormone (PTH) secretion, high bone turnover, and cardiovascular risks. ${ }^{3-5}$ In this regard, vitamin D supplementation is recommended for early CKD patients to delay the progression of CKD-MBD by maintaining adequate vitamin D levels. ${ }^{6}$ In these patients, monitoring of vitamin D and PTH levels is required to assess the efficacy of vitamin D treatment and identify the progression of CKD-MBD. However, since PTH changes at 3-6 months after vitamin D treatment, ${ }^{6}$ serum PTH level would not be a direct indicator of vitamin D efficacy. In addition, the change in the PTH level is small at the initial stage of CKD, so the progress of CKD-MBD cannot be evaluated only by PTH level. Thus, a new parameter is needed to evaluate and predict CKD-MBD in patients with slightly reduced renal function. ${ }^{7}$

Recent studies have indicated that fibroblast growth factor 23 (FGF23) plays a role in the regulation of mineral and bone metabolism from initial stage of CKD. ${ }^{5,8,9}$ Elevation in serum levels of FGF23 and increased calcium and phosphorus levels are frequently observed in patients with active vitamin $\mathrm{D}$ treatment (eg, 1,25-dihydroxyvitamin $\mathrm{D}_{3}$ $\left[1,25(\mathrm{OH})_{2} \mathrm{D}\right]$; calcitriol). ${ }^{5}$ Therefore, a change in FGF23 levels might be considered as an early indicator of MBD in CKD patients treated with vitamin D analog. ${ }^{9}$ High FGF23 is associated with atrial fibrillation, incidence of osteomalacia, faster disease progression in $\mathrm{CKD},{ }^{10}$ and increased mortality. ${ }^{11,12}$ Several previous studies have demonstrated that various factors including dietary calcium and phosphate intake, vitamin D production, and PTH levels can increase the change in serum FGF23 levels. Administration of vitamin D analogs has been shown to stimulate FGF23 synthesis directly ${ }^{13}$ and increase systemic phosphorus level indirectly. ${ }^{14-16}$ In addition, a high calcium diet led to increased serum calcium and FGF23 levels. ${ }^{17}$ High serum phosphate levels can also stimulate the expression and secretion of FGF23, which can induce excessive renal phosphate wasting. ${ }^{18}$ Thus, nephrologists have tried to regulate FGF23 through phosphate restriction and suppression of PTH levels using phosphate binders. ${ }^{719-21}$ As a result, lanthanum has appeared to be effective for lowering FGF23 levels and phosphate levels in patients with early stage of $\mathrm{CKD}$ and in those who are undergoing hemodialysis. ${ }^{19}$ Several studies have documented that sevelamer treatment decreases urinary excretion of phosphate and plasma FGF23 levels..$^{20,21}$ Although non-calcium-containing phosphate binders have been consistently shown to be able to lower FGF23 levels, there is no consistent result for calcium-containing phosphate binders. Some studies have shown a significant increase in serum levels of FGF23 after treatment with calcium acetate as a phosphate binder compared to treatment with sevelamer or lanthanum, ${ }^{7,22}$ but a significant change in FGF23 has not been observed in another study. ${ }^{20}$ In other studies aiming to compare between calcium carbonate and lanthanum, calcium-containing agent has shown no significant effect on FGF23 levels, unlike lanthanum carbonate. ${ }^{23,24}$ This is probably because complex mechanisms are involved in the regulation of mineral homeostasis. In addition, most of these studies have been performed in moderately progressed CKD patients, making it difficult to determine the effect of calcium on FGF23 level in early stage of CKD.

We hypothesized that elemental calcium would have a remarkable increase on serum FGF23 levels when it is treated in combination with calcitriol as vitamin $\mathrm{D}$ analog. Especially, it is currently unclear how FGF23 and PTH change as biomarkers of MBD in early CKD patients who are administered calcium and calcitriol together. Therefore, the aim of this study was to determine the effect of additional calcium treatment on change in serum FGF23 levels of patients receiving calcitriol.

\section{Methods}

\section{Study design and patients}

This study was designed as a randomized, parallel-group, open-labeled, and single-center trial. Adults of age 18-70 years with CKD stage 3 (defined as estimated glomerular filtration rate [GFR] of $30-60 \mathrm{~mL} / \mathrm{min} / 1.73 \mathrm{~m}^{3}$ ) were recruited from the Nephrology Department of a tertiary academic hospital in Korea. Exclusion criteria included known allergy to calcium carbonate; administration of calcium-containing phosphate binders within 3 months prior to study entry; history of hypercalcemia (corrected serum calcium $>10.5 \mathrm{mg} / \mathrm{dL}$ ), hypophosphatemia (serum phosphate $<2.5 \mathrm{mg} / \mathrm{dL}$ ), and very low PTH level (intact $\mathrm{PTH}[\mathrm{iPTH}]<5 \mathrm{pg} / \mathrm{mL}$ for adynamic bone disease) within 3 months prior to study entry; patients with bone pathologies or diseases requiring treatment unrelated to CKD-MBD; administration of concurrent medication, including steroids, bisphosphonates, other agents containing calcium, magnesium, and aluminum; comorbid diseases such as osteoporosis, congenital mineral metabolism abnormality, or history of surgeries that might affect mineral bone metabolism or alter bone status; patients diagnosed with rapidly progressive glomerulonephritis or in need of renal replacement therapy; patients with obstructive bowel diseases; and patients with $<2$ years of life expectancy.

The institutional review board of the Seoul National University Hospital approved the current study, and the study protocol was registered at ClinicalTrials.gov (NCT01748396). This study was conducted in accordance with the ethical 
standards of the Declaration of Helsinki. Written informed consent was obtained from all patients.

\section{Study intervention}

Participants were randomly assigned to preserve allocation concealment (in a 1:1 ratio) by computer-generated randomization sequence. One group received calcium carbonate (Cicibon ${ }^{\circledR}$ Tab; Huons Co., Ltd., Seoul, Korea) at $500 \mathrm{mg}$ three times daily with meal for 8 weeks and the other group received no such medication. All patients were treated with calcitriol (Bonky ${ }^{\circledR}$ Soft Cap; Yuyu Pharma Inc., Seoul, Korea) at $0.25 \mu \mathrm{g}$ daily. Dosages were kept uniform throughout the study duration.

\section{Data collection and analysis}

Blood samples were collected at study entry and at study completion to analyze serum levels of creatinine, calcium, phosphorus, albumin, iPTH, 25-hydroxyvitamin $\mathrm{D}_{3}$ (25(OH)D), and FGF23. PTH level was measured using an immunoradiometric assay, and FGF23 level was measured with a MILLIPLEXMAP enzyme-linked immunosorbent assay (MilliporeSigma, Billerica, MA, USA). The level of $25(\mathrm{OH}) \mathrm{D}$ was measured via radioimmunoassay. Blood samples taken to measure FGF23 and 25(OH)D levels were frozen at $<-70^{\circ} \mathrm{C}$ until analysis. Serum calcium levels were corrected for serum albumin levels.

The primary end point was the percentage change in serum FGF23 levels from baseline during 8 weeks. Secondary end points included percentage change differences in mineral parameters, including serum levels of calcium, phosphate, PTH, and 25(OH)D between the two groups. Safety assessment consisted of occurrences of adverse events and laboratory abnormalities such as hypercalcemia and/or hypophosphatemia during the study period. In addition, compliance of patient was assessed by pill count when drug bottles were returned after 8 weeks.

\section{Sample size and statistical analysis}

Based on CONSORT guideline and a previous study, ${ }^{7}$ sample size was calculated using $80 \%$ power and two-sided type I error of 0.05 , considering dropout rate of $20 \%$. In all, 30 patients (15 per group) were required for analysis. Demographic characteristics and biochemical parameters were described as mean $\pm \mathrm{SD}$ or median (interquartile range [IQR]) according to their distribution. Mean differences between the two groups at baseline and at the end of the study were analyzed using independent $t$-test or Mann-Whitney $U$ test for continuous variables and $\chi^{2}$ test for categorical variables as appropriate. Percentage changes from baseline within groups were analyzed using the same statistical techniques. Spearman's correlation for non-parametric data and Pearson's correlation for parametric data were used to analyze relationships between percentage changes in FGF23 levels and changes in serum levels of calcium and PTH. All tests were two sided, and statistical significance was considered when $P$-value was $<0.05$. All statistical analyses were performed using SPSS version 24.0 (IBM Corporation, Armonk, NY, USA).

\section{Results}

\section{Patient characteristics}

Participants were recruited and followed up during the period from August to November 2012. In all, 30 patients were randomly assigned to receive either calcium carbonate or no medication for 8 weeks (Figure 1). During the study period,

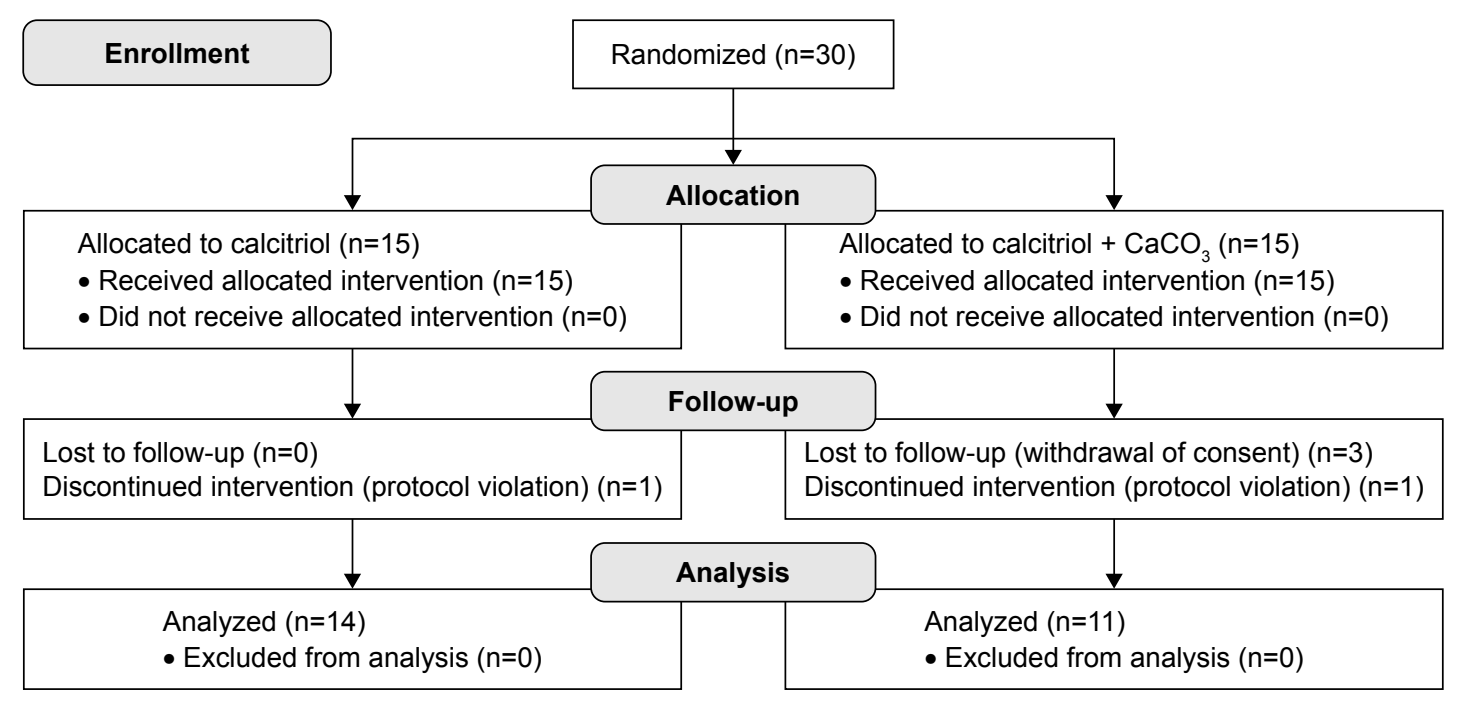

Figure I CONSORT flow diagram of participant enrollment.

Abbreviation: CONSORT, CONsolidated Standards Of Reporting Trials. 
Table I Baseline characteristics

\begin{tabular}{|c|c|c|c|}
\hline Characteristics & $\mathrm{CaCO}_{3}+$ calcitriol $(n=15)$ & Calcitriol $(n=15)$ & $P$-value \\
\hline Age (years) $)^{\ddagger}$ & $55.3 \pm 8.5$ & $56.0 \pm 9.9$ & 0.83 \\
\hline Gender, male** & $10(66.7)$ & II (73.3) & 1.00 \\
\hline CKD etiology** & & & 0.19 \\
\hline Diabetes & $2(13.3)$ & $7(46.7)$ & \\
\hline Hypertension & $2(13.3)$ & I (6.7) & \\
\hline $\lg A N$ & 7 (46.7) & $3(20.0)$ & \\
\hline Chronic GN (except IgAN) & I (6.7) & $2(13.3)$ & \\
\hline Others & $3(20.0)$ & $2(13.3)$ & \\
\hline Systolic BP $(\mathrm{mmHg})^{\ddagger}$ & $121.1 \pm 9.7$ & $|28.1 \pm| 4 . \mid$ & 0.13 \\
\hline Diastolic BP $(\mathrm{mmHg})^{\ddagger}$ & $76.1 \pm 8.1$ & $74.4 \pm 6.3$ & 0.53 \\
\hline GFR $\left(\mathrm{mL} / \mathrm{min} / \mathrm{l} .73 \mathrm{~m}^{2}\right)^{\ddagger}$ & $46.3 \pm 9.9$ & $46.4 \pm 9.2$ & 0.97 \\
\hline Serum calcium $(\mathrm{mg} / \mathrm{dL})^{\ddagger \S \S}$ & $9.43 \pm 0.32$ & $9.52 \pm 0.46$ & 0.52 \\
\hline Serum phosphorus (mg/dL) $)^{\ddagger \S}$ & $3.40 \pm 0.41$ & $3.63 \pm 0.54$ & 0.22 \\
\hline Serum $25(\mathrm{OH}) \mathrm{D}(\mathrm{ng} / \mathrm{mL})^{\ddagger}$ & $19.4 \pm 8.3$ & $16.4 \pm 7.4$ & 0.31 \\
\hline Intact PTH $(\mathrm{pg} / \mathrm{mL})^{\pi / \S}$ & $27.0(24.0-40.0)$ & $29.0(19.5-40.0)$ & 0.84 \\
\hline Serum FGF23 $(\mathrm{pg} / \mathrm{mL})^{\pi}$ & $24.9(23.6-31.2)$ & $24.2(23.1-29.6)$ & 0.41 \\
\hline
\end{tabular}

Notes: **Categorical data expressed as counts (frequencies in \%); continuous data expressed as ${ }^{\ddagger}$ mean \pm SD or ${ }^{\text {Imedian }}$ (interquartile range) as appropriate. ${ }^{\S}$ Normal range in CKD stage 3: serum calcium, $8.5-10.5 \mathrm{mg} / \mathrm{dL}$; serum phosphorus, $2.7-4.6 \mathrm{mg} / \mathrm{dL}$; and serum intact PTH $<70 \mathrm{pg} / \mathrm{mL}$.

Abbreviations: $25(\mathrm{OH}) \mathrm{D}, 25$-hydroxyvitamin $\mathrm{D}_{3}$; BP, blood pressure; $\mathrm{CaCO}_{3}$, calcium carbonate; CKD, chronic kidney disease; FGF23, fibroblast growth factor23; GFR, glomerular filtration rate; GN, glomerulonephritis; IgAN, immunoglobulin A nephropathy; PTH, parathyroid hormone.

four patients from the calcium treatment group (withdrawal of consent, $\mathrm{n}=3$; protocol violation, $\mathrm{n}=1$ ) and one patient from the other group (protocol violation, $n=1$ ) dropped out from the study. The remaining patients were included for analysis. Baseline characteristics of these patients enrolled in the current study are summarized in Table 1. Almost all patients were vitamin $\mathrm{D}$ deficient $(25(\mathrm{OH}) \mathrm{D}$ level $<30 \mathrm{ng} / \mathrm{mL}$ ). Mean serum calcium and phosphorus levels of the two groups were within the normal range (calcium normal range, $8.5-10.5 \mathrm{mg} / \mathrm{dL}$; phosphorus normal range, $2.7-4.6 \mathrm{mg} / \mathrm{dL})$. Median serum FGF23 level in these patients was at $24.5 \mathrm{pg} / \mathrm{mL}$ (IQR, 23.2-30.3 pg/mL), and median PTH level was at $27.5 \mathrm{pg} / \mathrm{mL}$ (IQR, 21.3-41.0 pg/mL; normal range, $<70 \mathrm{pg} / \mathrm{mL}$ ). Both groups were similar in demographic and biochemical parameters. There were no significant differences in baseline characteristics between the two groups. At the end of study, both groups demonstrated relatively high compliance rates (data not shown).

\section{Changes in CKD-MBD parameters}

\section{Changes in serum FGF23 levels}

The percentage change in the serum FGF23 level showed a trend to increase more in the combination group (calcium carbonate and calcitriol) than that in the calcitriol-alone group, although the difference was not statistically significant (with and without calcium carbonate: $\triangle \mathrm{FGF} 23[\%]=68.9 \% \pm 58.8 \%$ and $35.1 \% \pm 39.1 \%$, respectively, $P=0.097$; Table 2). After 8 weeks of treatment, mean serum FGF23 levels were increased significantly from baseline in both groups (with and without calcium carbonate: $\triangle F G F 23=18.8 \pm 16.8 \mathrm{pg} / \mathrm{mL}$ and $9.7 \pm 10.0 \mathrm{pg} / \mathrm{mL}$, respectively, both $P<0.01$; Figure $2 \mathrm{~A}$ ).

\section{Changes in serum calcium and phosphate levels}

Serum calcium levels were increased significantly from baseline in the treatment group with a combination of calcium and calcitriol (baseline and 8 weeks: $\mathrm{Ca}=9.3 \pm 0.2 \mathrm{mg} / \mathrm{dL}$ and $9.6 \pm 0.2 \mathrm{mg} / \mathrm{dL}$, respectively, $P=0.003)$. However, the

Table 2 Summary of difference in serum level changes of CKD-MBD parameters during the study

\begin{tabular}{llll}
\hline Parameters & $\mathbf{C a C O}_{3}+$ calcitriol $(\mathbf{n}=\mathbf{I I})$ & Calcitriol $(\mathbf{n}=\mathbf{I})$ & $\mathbf{P})$ \\
\hline Percentage change of serum calcium level $(\%)$ & $2.55(0.53,6.00)$ & $0.465(-4.96,7.42)$ & $0.075^{\mathrm{a}}$ \\
Percentage change of serum phosphorus level $(\%)$ & $5.17(-16.22,31.82)$ & $4.65(-20.66,31.92)$ & 0.94 \\
Percentage change of serum 25(OH)D level (\%) & $1.51(-13.83,22.15)$ & $-5.43(-23.37,8.54)$ & 0.16 \\
Percentage change of serum intact PTH level (\%) & $-1.27(-78.78,159.26)$ & $20.4(-64.24,143.33)$ & 0.54 \\
Percentage change of serum FGF23 level (\%) & $68.9(-9.86,159.22)$ & $35.1(-10.73,103.35)$ & 0.097 \\
\hline
\end{tabular}

Notes: ${ }^{a}$ Non-parametric test results using Mann-Whitney $U$ test. Data shown as mean percentage change $(95 \% \mathrm{Cl})$.

Abbreviations: $25(\mathrm{OH}) \mathrm{D}, 25$-hydroxyvitamin $\mathrm{D}_{3} ; \mathrm{CaCO}_{3}$, calcium carbonate; $\mathrm{Cl}$, confidence interval; CKD-MBD, chronic kidney disease-mineral and bone disorder; FGF23, fibroblast growth factor23; PTH, parathyroid hormone. 
A

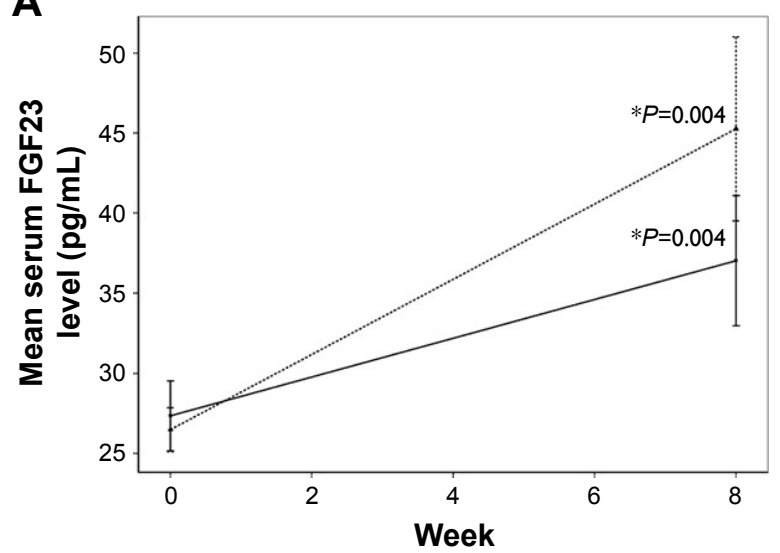

C

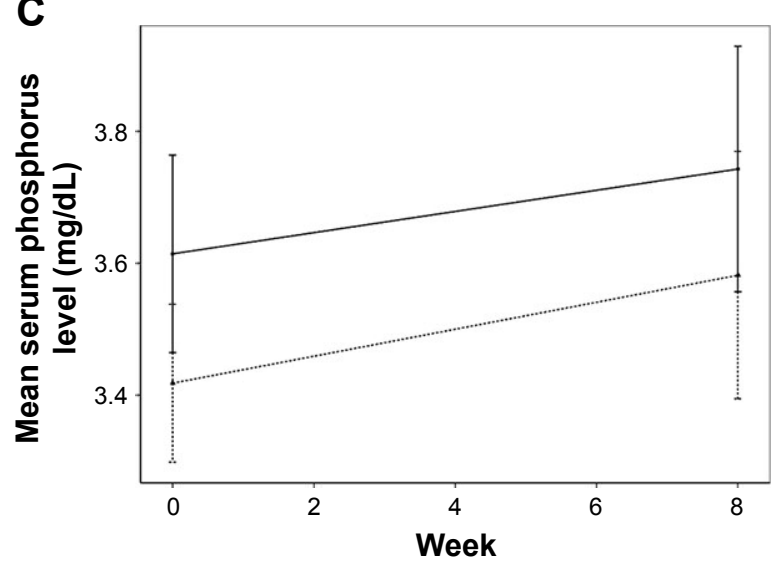

B

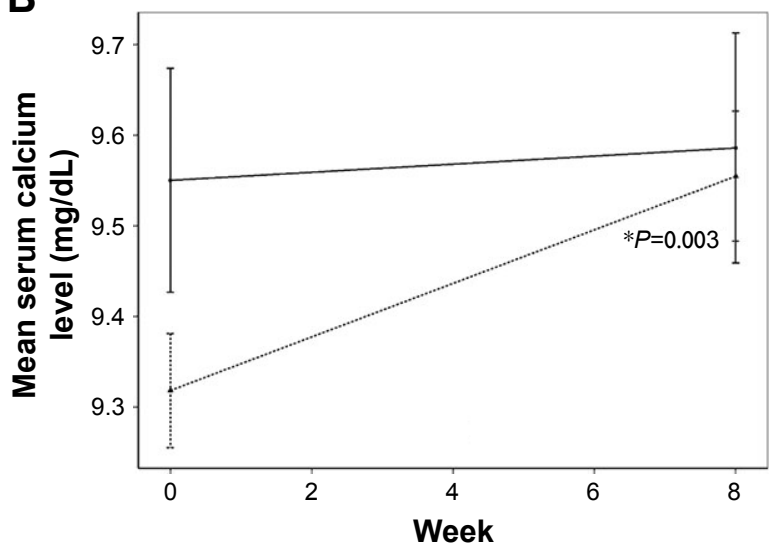

D

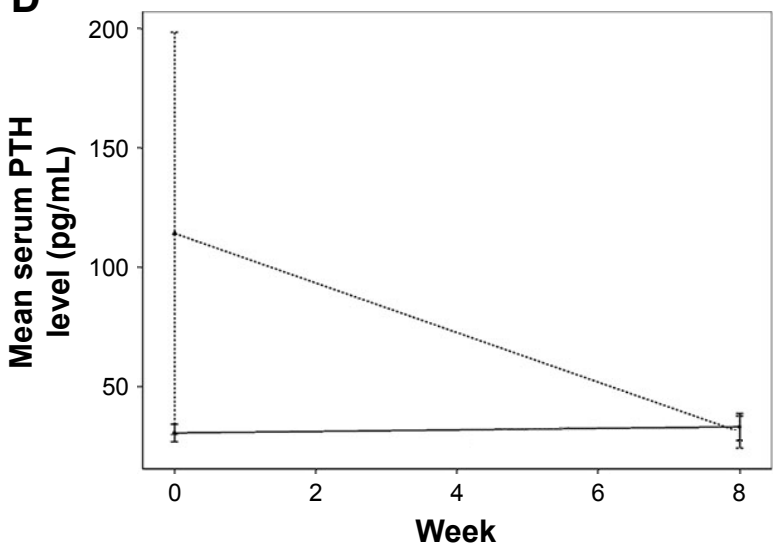

- Calcitriol - Calcitriol + calcium carbonate

Figure 2 Mean changes in concentrations of serum FGF23, calcium, phosphate, and PTH over 8-week treatment in two groups.

Notes: (A) Mean serum FGF23 level (pg/mL) in the treatment group over 8 weeks. (B) Mean serum calcium level (mg/dL) in the treatment group over 8 weeks. (C) Mean serum phosphorus level $(\mathrm{mg} / \mathrm{dL})$ in the treatment group over 8 weeks. (D) Mean serum intact PTH level $(\mathrm{pg} / \mathrm{mL})$ in the treatment group over 8 weeks. $* P<0.05$.

Abbreviations: FGF23, fibroblast growth factor 23; PTH, parathyroid hormone.

calcitriol treatment-alone group showed no significant difference in serum calcium levels (baseline and 8 weeks: $\mathrm{Ca}=9.6 \pm 0.5 \mathrm{mg} / \mathrm{dL}$ and $9.6 \pm 0.5 \mathrm{mg} / \mathrm{dL}$, respectively, $P=0.77$; Figure 2B). Percentage change in the serum calcium level from baseline did not show significant difference between the two groups (with and without calcium carbonate: $\Delta \mathrm{Ca}$ $(\%)=2.6 \% \pm 2.2 \%$ and $0.5 \% \pm 4.6 \%$, respectively, $P=0.075$; Table 2). Both percentage changes and mean changes in serum phosphorus levels from baseline to 8 weeks in both groups were not statistically significant (Table 2 and Figure 2C, respectively).

\section{Changes in other CKD-MBD parameters}

There was no statistically significant reduction between serum PTH levels at 0 and 8 weeks after combination treatment, but their levels were slightly increased in the calcitriol treatment-alone group (with and without calcium carbonate: $\triangle \mathrm{iPTH}(\%)=-1.3 \% \pm 89.8 \%$ and $20.4 \% \pm 82.1 \%$, respectively; Table 2 and Figure 2D). During the study period, concentrations of $25(\mathrm{OH}) \mathrm{D}$ were not significantly changed in either group (with and without calcium carbonate: $\Delta 25(\mathrm{OH}) \mathrm{D}=1.5 \% \pm 13.2 \%$ and $-5.4 \% \pm 11.0 \%$, respectively; Table 2).

\section{Correlation analysis for changes in FGF23 levels}

Before intervention, serum FGF23 levels were not correlated with any demographic or clinical parameters. During the study period, significant positive correlations were found between percentage changes in serum FGF23 levels and percentage changes in serum calcium levels in the combination treatment group but not in calcitriol treatment-alone group (combination and calcitriol: Spearman's correlation coefficient $=0.63$ and $0.18, P=0.038$ and 0.55 , respectively; Figure 3 ). However, percentage change in the serum PTH level was not significantly correlated with percentage change in the serum FGF23 level in either treatment group (combination and calcitriol: Pearson's 

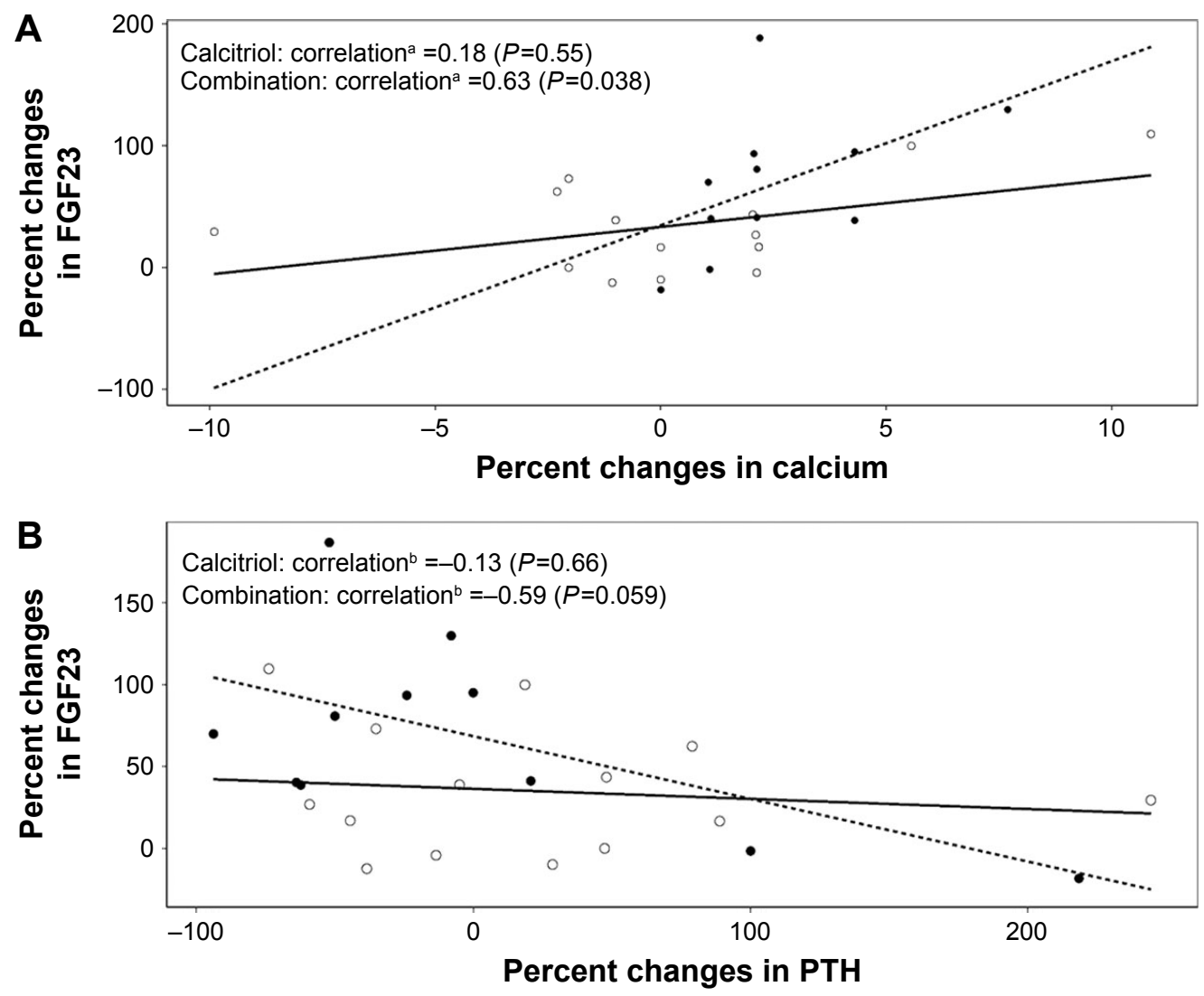

$\ominus$ Calcitriol $\bullet$ Calcitriol + calcium carbonate

Figure 3 Correlation between percentage change of FGF23 and calcium and PTH in the treatment group (combination versus calcitriol).

Notes: (A) Percentage change from baseline in the serum FGF23 level versus percentage change from baseline in the serum calcium level. (B) Percentage change from baseline in the serum FGF23 level versus percent change from baseline in the serum PTH level. 'Spearman's correlation coefficient results. 'Pearson's correlation coefficient results. Abbreviations: FGF23, fibroblast growth factor 23; PTH, parathyroid hormone.

correlation coefficient $=-0.59$ and $-0.13, P=0.059$ and 0.66 , respectively; Figure 3).

\section{Safety}

We did not observe laboratory abnormalities such as hypercalcemia or hypophosphatemia throughout the study duration. For adverse events, only one case of mild gastrointestinal discomfort was reported in the calcitriol-alone group. There were no serious adverse events.

\section{Discussion}

We performed a randomized trial to estimate the impact of additional calcium treatment on serum FGF23 levels in CKD-MBD patients receiving combination treatment of calcium carbonate and calcitriol. During the study period, the calcium and calcitriol combination treatment group showed a significant increase in both serum FGF23 level and calcium level, compared to the calcitriol treatment-alone group. These results suggest that additional calcium carbonate might result in upregulation of serum FGF23 levels by acting as a calcium supplement rather than as a phosphorus binder.

Several reasons might explain why FGF23 level was elevated when calcium and vitamin D were used together in CKD patients. First, activated vitamin D can regulate FGF23 expression and potentially regulate $\mathrm{PTH}$. In both animal and human studies, administration of calcitriol has increased serum FGF23 levels due to a direct or indirect action of vitamin D on FGF23. For example, calcitriol acts directly on a vitamin D response element (VDRE) located upstream of the FGF23 promoter, ${ }^{25,26}$ resulting in the production of FGF23. ${ }^{27}$ In addition, calcitriol promotes the synthesis of epithelial calcium channels ${ }^{28,29}$ and activates the plasma membrane calcium pumps. ${ }^{30,31}$ It can also induce the formation of calcium-binding proteins. ${ }^{32}$ These mechanisms can induce calcium absorption from the gastrointestinal tract, which might continuously stimulate FGF23 release. ${ }^{5}$ Burnett-Bowie et $\mathrm{al}^{33}$ and Alvarez et $\mathrm{al}^{34}$ have reported that FGF23 levels are significantly increased after 12 weeks of ergocalciferol or 
cholecalciferol treatment at 50,000 international units (IUs) in contrast with placebo carried out in patients with relatively normal kidney functions. Wesseling-Perry et a ${ }^{35}$ have also demonstrated that FGF23 levels are increased after treatment with either calcitriol or doxercalciferol using various amounts of vitamin D supplementation. These results suggest that the absorbed amount of vitamin D can influence the concentration of FGF23, regardless of renal function of patients. However, we did not observe the significant elevation in FGF23 levels in calcitriol-alone group. This was probably due to difference in absorbed amounts of vitamin D. In fact, amounts of vitamin D analogs in the studies by BurnettBowie et $\mathrm{al}^{33}$ and Alvarez et $\mathrm{al}^{34}$ were very high when they were converted to the equivalent doses of calcitriol.

Second, administration of calcium may itself induce a rise in circulating FGF23, independent of vitamin D. Vervloet et $\mathrm{a}^{36}$ have reported that serum FGF23 levels are increased during high dietary calcium intake, whereas levels of both PTH and $1,25(\mathrm{OH})_{2} \mathrm{D}$ are decreased. Kobayashi et al ${ }^{37}$ have reported that calcium supplementation can significantly increase FGF23 mRNA abundance independent of vitamin D concentration using vitamin-D-receptor null mice. These studies suggest that serum calcium has positive and significant correlation with FGF23 level. Similarly, serum FGF23 levels are decreased at hypocalcemic status despite high PTH and $1,25(\mathrm{OH})_{2}$ D levels. ${ }^{38}$ However, as noted earlier, FGF23 was not significantly increased in studies using calcium acetate. This was probably due to low amount of elemental calcium in calcium acetate. Calcium acetate contains less elemental calcium than calcium carbonate ( $25 \%$ versus $40 \%$, respectively), ${ }^{6}$ although it has superior phosphate-binding capacity than calcium carbonate. ${ }^{39}$ Thus, contents of calcium in calcium carbonate might have outbalanced the effect of phosphorous binding, resulting in more increase in serum FGF23 levels.

Finally, in our study, the significant increase in serum FGF23 levels following combination use of calcitriol and calcium carbonate might reflect that vitamin $D$ could facilitate calcium absorption. As described earlier, when calcitriol is combined with calcium, calcium uptake in the gastrointestinal tract is promoted, leading to elevated calcium levels in the blood. These results were also observed in our study, in which serum calcium level was significantly elevated after 8 weeks in the combination treatment group. The stimulatory effect of calcium was further enhanced by vitamin $D$ analog. This consequently suggests that the risk of adverse effects might be higher due to elevated FGF23 levels.

Meanwhile, despite these changes in calcium and FGF23 levels, no significant change in serum levels of phosphorus or PTH was observed in our study. Previous study has shown that vitamin D could suppress PTH directly in the parathyroid gland.$^{40}$ However, in our study, only the combination treatment group lowered serum PTH levels from baseline compared to the calcitriol-alone group, although not statistically significant. It seems that the combination of vitamin D and calcium suppresses PTH directly or indirectly by increasing calcium concentration. Serum phosphorus concentration was not significantly changed in either group during the study period. These results indicate that effects of vitamin $\mathrm{D}$ analog on FGF23 are not likely to be mediated by changes in serum phosphorus or PTH level. Rather, they might be mediated directly by serum calcium levels in early CKD patients. Since calcium acts directly on calcium-sensing receptor of parathyroid glands to inhibit the secretion of $\mathrm{PTH},{ }^{41}$ elevated calcium might inhibit PTH secretion. Therefore, it is more important to monitor serum FGF23 levels and serum levels of phosphorus, vitamin D, or PTH status in the patients under vitamin $\mathrm{D}$ and calcium treatments.

To the best our knowledge, this is a well-done study that identifies the stimulatory effect of additional calcium on changes in serum FGF23 levels. In addition, our correlation analysis suggests that change in serum calcium level is a potential biomarker for prediction of increased FGF23 in patients treated with vitamin D analogs and/or calcium-based phosphate binders. This new insight can be applied to clinical practice for predicting the risk of cardiovascular diseases related to high FGF23 levels. Nevertheless, our study had some limitations. We could not identify the involvement of FGF23 levels in bone metabolism change, a direct marker of CKDMBD. This might be due to the relatively small number of patients used in this study with a relative short period of monitoring for the formation and degradation of bone. Although assumptions made in calculating sample size estimations were performed based on a previous study, the small number of patients might have limited us in achieving results of greater power. In addition, as mentioned earlier, because we used a relatively small dose of calcitriol, the absorbed amount of vitamin $\mathrm{D}$ might be low. Thus, larger randomized controlled trials of vitamin D analogs at various doses are needed in the future to achieve improved results. Further studies are warranted to determine the long-term clinical impact of combination treatment on serum levels of FGF23 associated with cardiovascular disease morbidity and mortality.

\section{Conclusion}

Additional calcium carbonate to calcitriol treatment showed greater effects on changes in serum FGF23 levels than 
calcitriol alone. This might be due to synergistic effect between calcium carbonate and calcitriol by increasing intestinal calcium absorption. Our results suggest that it is important to regularly monitor serum calcium and FGF23 levels in patients having risk of increased calcium absorption due to combination treatment with calcium carbonate and calcitriol, even if their serum phosphorus levels are within normal range.

\section{Acknowledgments}

This work was supported by a National Research Foundation of Korea (NRF) grant, funded by the Korean government (MEST; NRF-2009-0081414) and the Ministry of Science, ICT \& Future Planning (NRF-2014M3C1B3064644), and by the BK21 Plus Program. Yuyu Pharma Inc. provided Bonky Soft Capsules, but otherwise had no role in the design, analysis, or interpretation of the results, or the writing of the manuscript.

\section{Disclosure}

The authors report no conflicts of interest in this work.

\section{References}

1. Vaziri ND, Hollander D, Hung EK, Vo M, Dadufalza L. Impaired intestinal absorption of vitamin D3 in azotemic rats. Am J Clin Nutr. 1983; 37(3):403-406.

2. Moe S, Drueke T, Cunningham J, et al. Definition, evaluation, and classification of renal osteodystrophy: a position statement from kidney disease: improving global outcomes (KDIGO). Kidney Int. 2006;69(11): 1945-1953.

3. Berndt TJ, Schiavi S, Kumar R. "Phosphatonins" and the regulation of phosphorus homeostasis. Am J Physiol Renal Physiol. 2005;289(6): F1170-F1182.

4. Ritz E, Gross ML, Dikow R. Role of calcium-phosphorous disorders in the progression of renal failure. Kidney Int Suppl. 2005;99:S66-S70.

5. Mehrotra R, Kermah DA, Salusky IB, et al. Chronic kidney disease, hypovitaminosis D, and mortality in the United States. Kidney Int. 2009; 76(9):977-983.

6. National Kidney Foundation. K/DOQI clinical practice guidelines for bone metabolism and disease in chronic kidney disease. Am J Kidney Dis. 2003;42(4 suppl 3):S1-S201.

7. Oliveira RB, Cancela AL, Graciolli FG, et al. Early control of PTH and FGF23 in normophosphatemic CKD patients: a new target in CKD-MBD therapy? Clin J Am Soc Nephrol. 2010;5(2):286-291.

8. Evenepoel P, Meijers B, Viaene L, et al. Fibroblast growth factor-23 in early chronic kidney disease: additional support in favor of a phosphate-centric paradigm for the pathogenesis of secondary hyperparathyroidism. Clin J Am Soc Nephrol. 2010;5(7):1268-1276.

9. Hu P, Xuan Q, Hu B, Lu L, Wang J, Qin YH. Fibroblast growth factor-23 helps explain the biphasic cardiovascular effects of vitamin D in chronic kidney disease. Int J Biol Sci. 2012;8(5):663-671.

10. Mathew JS, Sachs MC, Katz R, et al. Fibroblast growth factor-23 and incident atrial fibrillation: the multi-ethnic study of atherosclerosis (MESA) and the cardiovascular health study (CHS). Circulation. 2014; 130(4):298-307.

11. Kendrick J, Cheung AK, Kaufman JS, et al. FGF-23 associates with death, cardiovascular events, and initiation of chronic dialysis. J Am Soc Nephrol. 2011;22(10):1913-1922.
12. Isakova T, Xie H, Yang W, et al. Fibroblast growth factor 23 and risks of mortality and end-stage renal disease in patients with chronic kidney disease. JAMA. 2011;305(23):2432-2439.

13. Liu S, Tang W, Zhou J, et al. Fibroblast growth factor 23 is a counterregulatory phosphaturic hormone for vitamin D. J Am Soc Nephrol. 2006; 17(5):1305-1315.

14. Wolf M. Update on fibroblast growth factor 23 in chronic kidney disease. Kidney Int. 2012;82(7):737-747.

15. Haussler MR, Whitfield GK, Kaneko I, et al. The role of vitamin D in the FGF23, klotho, and phosphate bone-kidney endocrine axis. Rev Endocr Metab Disord. 2012;13(1):57-69.

16. Fukagawa M, Kazama JJ. With or without the kidney: the role of FGF23 in CKD. Nephrol Dial Transplant. 2005;20(7):1295-1298.

17. Shimada T, Yamazaki Y, Takahashi M, et al. Vitamin D receptorindependent FGF23 actions in regulating phosphate and vitamin D metabolism. Am J Physiol Renal Physiol. 2005;289(5):F1088-F1095.

18. Razzaque MS. The FGF23-Klotho axis: endocrine regulation of phosphate homeostasis. Nat Rev Endocrinol. 2009;5(11):611-619.

19. Gonzalez-Parra E, Gonzalez-Casaus ML, Galan A, et al. Lanthanum carbonate reduces FGF23 in chronic kidney disease Stage 3 patients. Nephrol Dial Transplant. 2011;26(8):2567-2571.

20. Yilmaz MI, Sonmez A, Saglam M, et al. Comparison of calcium acetate and sevelamer on vascular function and fibroblast growth factor 23 in CKD patients: a randomized clinical trial. Am J Kidney Dis. 2012; 59(2):177-185.

21. Lin HH, Liou HH, Wu MS, Lin CY, Huang CC. Long-term sevelamer treatment lowers serum fibroblast growth factor 23 accompanied with increasing serum Klotho levels in chronic haemodialysis patients. Nephrology (Carlton). 2014;19(11):672-678.

22. Block GA, Wheeler DC, Persky MS, et al. Effects of phosphate binders in moderate CKD. J Am Soc Nephrol. 2012;23(8):1407-1415.

23. Soriano S, Ojeda R, Rodriguez M, et al. The effect of phosphate binders, calcium and lanthanum carbonate on FGF23 levels in chronic kidney disease patients. Clin Nephrol. 2013;80(1):17-22.

24. Chang YM, Tsai SC, Shiao CC, et al. Effects of lanthanum carbonate and calcium carbonate on fibroblast growth factor 23 and hepcidin levels in chronic hemodialysis patients. Clin Exp Nephrol. Epub 2016 Dec 7.

25. Levine BS, Kleeman CR, Felsenfeld AJ. The journey from vitamin Dresistant rickets to the regulation of renal phosphate transport. Clin J Am Soc Nephrol. 2009;4(11):1866-1877.

26. Barthel TK, Mathern DR, Whitfield GK, et al. 1,25-dihydroxyvitamin D3/VDR-mediated induction of FGF23 as well as transcriptional control of other bone anabolic and catabolic genes that orchestrate the regulation of phosphate and calcium mineral metabolism. J Steroid Biochem Mol Biol. 2007;103(3-5):381-388.

27. Quarles LD. Skeletal secretion of FGF-23 regulates phosphate and vitamin D metabolism. Nat Rev Endocrinol. 2012;8(5):276-286.

28. Norman AW. Intestinal calcium absorption: a vitamin D-hormonemediated adaptive response. Am J Clin Nutr. 1990;51(2):290-300.

29. Wood RJ, Tchack L, Taparia S. 1,25-dihydroxyvitamin D3 increases the expression of the CaT1 epithelial calcium channel in the Caco-2 human intestinal cell line. BMC Physiol. 2001;1:11.

30. Christakos S, Dhawan P, Porta A, Mady LJ, Seth T. Vitamin D and intestinal calcium absorption. Mol Cell Endocrinol. 2011;347(1-2): 25-29.

31. Zelinski JM, Sykes DE, Weiser MM. The effect of vitamin D on rat intestinal plasma membrane CA-pump mRNA. Biochem Biophys Res Commun. 1991;179(2):749-755.

32. Christakos S, Gabrielides C, Rhoten WB. Vitamin D-dependent calcium binding proteins: chemistry, distribution, functional considerations, and molecular biology. Endocr Rev. 1989;10(1):3-26.

33. Burnett-Bowie SA, Leder BZ, Henao MP, Baldwin CM, Hayden DL, Finkelstein JS. Randomized trial assessing the effects of ergocalciferol administration on circulating FGF23. Clin J Am Soc Nephrol. 2012;7(4): 624-631. 
34. Alvarez JA, Law J, Coakley KE, et al. High-dose cholecalciferol reduces parathyroid hormone in patients with early chronic kidney disease: a pilot, randomized, double-blind, placebo-controlled trial. Am J Clin Nutr. 2012;96(3):672-679.

35. Wesseling-Perry K, Pereira RC, Sahney S, et al. Calcitriol and doxercalciferol are equivalent in controlling bone turnover, suppressing parathyroid hormone, and increasing fibroblast growth factor-23 in secondary hyperparathyroidism. Kidney Int. 2011;79(1):112-119.

36. Vervloet MG, van Ittersum FJ, Buttler RM, Heijboer AC, Blankenstein MA, ter Wee PM. Effects of dietary phosphate and calcium intake on fibroblast growth factor-23. Clin J Am Soc Nephrol. 2011;6(2):383-389.

37. Kobayashi K, Imanishi Y, Miyauchi A, et al. Regulation of plasma fibroblast growth factor 23 by calcium in primary hyperparathyroidism. Eur J Endocrinol. 2006;154(1):93-99.
38. Rodriguez-Ortiz ME, Lopez I, Munoz-Castaneda JR, et al. Calcium deficiency reduces circulating levels of FGF23. J Am Soc Nephrol. 2012; 23(7):1190-1197.

39. Mai ML, Emmett M, Sheikh MS, Santa Ana CA, Schiller L, Fordtran JS. Calcium acetate, an effective phosphorus binder in patients with renal failure. Kidney Int. 1989;36(4):690-695.

40. El-Agroudy AE, El-Husseini AA, El-Sayed M, Ghoneim MA. Preventing bone loss in renal transplant recipients with vitamin D. J Am Soc Nephrol. 2003;14(11):2975-2979.

41. Moe SM. Disorders involving calcium, phosphorus, and magnesium. Prim Care. 2008;35(2):215-237, v-vi.

\section{Publish your work in this journal}

Therapeutics and Clinical Risk Management is an international, peerreviewed journal of clinical therapeutics and risk management, focusing on concise rapid reporting of clinical studies in all therapeutic areas outcomes, safety, and programs for the effective, safe, and sustained use of medicines. This journal is indexed on PubMed Central, CAS,
EMBase, Scopus and the Elsevier Bibliographic databases. The manuscript management system is completely online and includes a very quick and fair peer-review system, which is all easy to use. Visit http://www.dovepress.com/testimonials.php to read real quotes from published authors.

Submit your manuscript here: http://www.dovepress.com/therapeutics-and-clinical-risk-management-journal 